Artigo

DOI | 10.21680/1981-1802.2021v59n60ID25671

\title{
A produção periódica estudantil oitocentista
}

\author{
Laís Pacifico Martineli \\ Maria Cristina Gomes Machado \\ Universidade Estadual de Maringá (Brasil)
}

\section{Resumo}

Objetivamos mapear as publicações periódicas estudantis do período oitocentista presentes no acervo da Hemeroteca Digital Brasileira. Indagamos sobre a produção de periódicos publicados por estudantes brasileiros no Império (1 822-1889) em diferentes espaços geográficos do País. Adotamos como aporte teórico os pressupostos de António Nóvoa (2002) sobre a concepção e a organização de um repertório analítico de periódicos. Após o levantamento, compartilhamos um mapeamento contendo títulos, locais, datas de publicação e números dos jornais discentes disponibilizados no acervo. A investigação evidencia uma tendência de crescimento quantitativo na publicação de periódicos estudantis entre 1840 e 1870 e a consolidação dessa prática em 1880. Tratou-se de um movimento estudantil nacional, pois os periódicos foram publicados nas principais capitais provinciais, com incidências em regiões interioranas. Muitos vinculavam-se a associações literárias e evidenciavam, no título, a predileção pela produção de jornais literários. $\bigcirc$ mapeamento ratificou a dificuldade de manutenção desses periódicos que, embora numerosos, possuíam publicações efêmeras.

Palavras-chave: Educação. História da educação. Século XIX. Imprensa estudantil.

\section{The student journal production in the nineteenth-century}

\begin{abstract}
We have the aim to map the students' journal publications from the nineteenth-century in the Hemeroteca Digital Brasileira (Brazilian Journals Digital Library) collection. Thus, we asked about the production of journals published by Brazilian students during the Imperial period (1 822-1889) in different geographic spaces of the country. We adopted as theoretical basis the assumptions of António Nóvoa (2002) about the conception and organization of an analytical repertory of journals. After the survey, we shared a mapping containing titles, places, publication dates and numbers of the student journals available in the collection. The investigation shows a trend of quantitative growth in the student journals publication between 1840 and 1870, and the consolidation of this practice in 1880. It was a national student movement, since the journals were published in the main provincial capitals, with incidence in the interior regions. Many were linked to literary associations and evidenced, in the title, the predilection for the production of literary journals. The mapping ratified the difficulty of students of maintaining these journals, that, although numerous, had ephemeral publications.
\end{abstract}

Keywords: Education. History of education. 19th century. Student press. 
A produção periódica estudantil oitocentista

\section{La producción periodística estudiantil en el siglo XIX}

\section{Resumen}

Nuestro objetivo fue mapear las publicaciones periódicas de los estudiantes del siglo XIX en la colección de la Hemeroteca Digital Brasileña. Preguntamos sobre la producción de los periódicos publicados por estudiantes brasileños durante el Imperio (1822-1889) en diferentes espacios geográficos del país. Adoptamos como base teórica los supuestos de António Nóvoa (2002) sobre la concepción y organización de un repertorio analítico de periódicos. Después el levantamiento, compartimos un mapeo que contiene títulos, ubicaciones, fechas de publicación y números de periódicos para estudiantes disponibles en la colección. La investigación evidencia una tendencia de crecimiento cuantitativo en la publicación de periódicos estudiantiles entre 1840 y 1870 y la consolidación de esta práctica en 1880 . Fue un movimiento estudiantil nacional, ya que los periódicos fueron publicados en las principales capitales de la provincia, con incidencias en las regiones del interior. Muchos estaban vinculados a asociaciones literarias y evidenciaban, en el título, la producción de periódicos literarios. El mapeo ratificó la dificultad de mantenimiento de estos periódicos que, aunque numerosos, tenían publicaciones efímeras.

Palabras clave: Educación. Historia de la educación. Siglo XIX. Prensa estudiantil.

\section{Introdução}

O tema central deste texto é a produção periódica estudantil do século XIX. Sobretudo após a segunda metade do regime imperial, estudantes brasileiros de diversas regiões do país empenharam-se na publicação de jornais estudantis. A existência desse tipo de imprensa foi indicada pelo autor Leonardo Arroyo (1918-1985), no livro Literatura infantil brasileira, publicado em 1968. Em especial, no quinto capítulo "Imprensa infantil e escolar", Arroyo (201 1) elencou uma longa lista de títulos de jornais infantis (materiais de leitura escritos pelos adultos às crianças) e de jornais escolares (elaborados por alunos em instituições escolares), cujas publicações ocorreram durante todo o período que corresponde ao regime imperial, em províncias do sul ao norte do país.

O estudo desse autor nos instigou a iniciarmos o levantamento desses documentos históricos que, devido à sua notabilidade no período como material de leitura elaborado pelos próprios estudantes para seus pares, foram classificados por ele como parte da "pré-história da literatura infantil brasileira" (ARROYO, 201 1). O nosso objetivo com esse texto é mapear as publicações periódicas estudantis oitocentistas do acervo da Hemeroteca Digital Brasileira. 
Indagamos sobre a produção de periódicos estudantis no Império no Brasil (1822-1889) em diferentes espaços geográficos do país.

Optamos por realizar o levantamento dos periódicos estudantis no acervo da Hemeroteca Digital da Biblioteca Nacional Digital por entendermos que ele fornece um panorama nacional do que foi produzido pela imprensa brasileira, em especial, para nós, pela classe estudantil no período imperial. A investigação feita na Hemeroteca evidenciou um expressivo contingente de títulos de jornais estudantis durante a monarquia brasileira, o que, por si só, justifica a necessidade de um mapeamento desses documentos e de pesquisas que se debrucem sobre eles.

Os pressupostos de António Nóvoa (2002) acerca da concepção e da organização de um repertório analíitico das publicações periódicas de Portugal, na área da educação e ensino, foram adotados como aporte teórico para a elaboração do mapeamento dos periódicos estudantis brasileiros oitocentistas. Com base na relevância da imprensa periódica para a história da educação, o autor pontuou três motivos para a elaboração do repertório: o interesse em "[...] produzir instrumentos de acesso a uma fonte de grande riqueza, a afirmação da imprensa como objeto de estudo autônomo e o desejo de contribuir para a renovação conceitual e metodológica da História da Educação" (NÓVOA, 2002, p. 14).

O repertório exposto por António Nóvoa foi elaborado em algumas fases. Após selecionar as fontes, os dados de cada periódico selecionado foram incluídos em fichas de análise compostas por cabeçalho, objetivo do periódico, conteúdo e dados técnicos, além de índices finais e classificação por tipologia de publicação. Em virtude das limitações deste artigo, expomos a etapa de seleção das fontes por meio do mapeamento. O processo de seleção das fontes permitiu, além disso, realizar a classificação dos jornais escritos por estudantes em tipologias.

Buscamos, por este mapeamento, a catalogação dos periódicos estudantis do século XIX, disponíveis na Hemeroteca Digital Brasileira, para acesso e estudo por parte dos pesquisadores que se interessem pelo conteúdo desses materiais. $\bigcirc$ esforço de mapear os jornais dos estudantes revela muitas características desse movimento estudantil e desses jornais, pois evidencia uma efervescente mobilização protagonizada por jovens brasileiros em idade escolar, de diversas províncias do Brasil, em produzir periódicos que, naquele 
momento, cumpriram o papel de preencher uma lacuna por materiais de leitura para a mocidade brasileira, além de servir como um espaço de escrita e expressão das ideias juvenis.

Machado e Rodrigues (2017, p. 254) defendem que é "[...] enriquecedor ao campo educacional fazer uso de fontes que possibilitem acesso a múltiplas formas de representação do objeto que se pretende estudar". Os periódicos escritos por estudantes para seus pares durante o Império brasileiro são documentos ímpares para as pesquisas em História da Educação, por conter e oferecer "[...] muitas perspectivas para a compreensão da história da educação e do ensino" (BASTOS, 2015, p. 22). Essas publicações foram registros elaborados por sujeitos que não eram ouvidos ou priorizados no fazer historiográfico e, por isso, expunham a educação e o ensino sob uma nova ótica, isto é, sob a ótica daqueles que eram o alvo da educação. Além disso, por serem expressão do pensamento estudantil, evidenciam o posicionamento dos estudantes diante das questões em pauta no período, como a literatura, a escravidão, a economia, a religião, a ciência, a moral, dentre outros.

mapeamento dos periódicos estudantis preenche uma lacuna de estudos que tomam como objeto a imprensa estudantil do regime imperial. 4 Estudos que adotam a imprensa elaborada por estudantes no século XIX como fonte ou objeto são reduzidas e, por isso, trata-se de um campo de pesquisa aberto, promissor e de necessário desbravamento. Dentre as pesquisas encontradas, destacamos, em especial, o artigo de Mônica Yumi Jinzenzi (2017), que apresenta o resultado de uma busca por impressos publicados no período imperial que continham, em seu título, as palavras juventude, mocidade e derivados. Nesse estudo, a autora divulgou uma lista de periódicos juvenis /alguns deles, estudantis) e analisou as representações sobre a juventude, os repertórios para leitura neles publicados e as suas práticas de escrita literária.

$\bigcirc$ texto está organizado em duas partes. No primeiro momento, compartilhamos o caminho percorrido para selecionar os periódicos estudantis no acerco digital da Hemeroteca. No segundo momento, realizamos a exposição do resultado dessa busca por meio de um mapeamento que apresenta os títulos encontrados, os locais e datas de publicação, bem como os números disponibilizados no acervo digital. 


\section{Agulhas no palheiro: caminho metodológico para rastrear os jornais estudantis}

Neste tópico, relatamos o caminho metodológico percorrido para busca dos jornais estudantis publicados no Império brasileiro na Hemeroteca Digital Brasileira. Localizar os periódicos estudantis no acervo da Hemeroteca Digital foi como encontrar "agulhas no palheiro" diante da quantidade de títulos desse acervo. A busca pelos periódicos não ocorreu fortuitamente, pois consagramos três critérios para a seleção das fontes: 1) disponibilidade de acesso aos jornais na Hemeroteca Digital Brasileira; 2) período de publicação correspondente ao regime imperial, período delimitado para esta investigação; 3) presença de algum indício de que o jornal tenha sido escrito por estudantes.

Para atender ao primeiro critério, estipulamos palavras-chave que foram inseridas na ferramenta de busca por "Periódico" no site da Hemeroteca Digital. As palavras-chave escolhidas foram aquelas que, de alguma forma, remetiam à educação, aos estudantes, à mocidade e às instituições de ensino: educação; instrução/instrucção; infância; infantil; mocidade; estudante (s); estudantil (is); juventude; juvenil; escola/ eschola; escolar/escholar; escolástico/escholastico (a); estudo; ensino; colégio/collegio; colegial/colegial; lyceu; ginásio/gymnasio; alunos/alumnos. Nessa primeira etapa, encontramos 214 periódicos dos mais variados tipos e formatos, como documentos oficiais (boletins, anais, entre outros) e periódicos diversificados (alguns escritos para adultos, crianças, jovens, estudantes de ensino superior ou da mocidade estudiosa).

Aos 214 periódicos foi aplicado o segundo critério, isto é, o período histórico de publicação correspondente ao período do regime imperial. Dentre os 214 periódicos, 124 jornais foram publicados no Império e 90 no período republicano. Além disso, foi possível constatar que, dentre os 124 periódicos publicados no período imperial, 84 eram de 1870 e 1880, isto é, aproximadamente $70 \%$, o que indica, dentre outros fatores, que a organização de periódicos se tornou um hábito, ou uma prática, entre a classe estudantil naquele momento.

Após a identificação dos periódicos publicados no período imperial, a partir da busca por palavras-chave, buscamos as "menções de responsabilidade" (NÓVOA, 2002), isto é, alguma declaração sobre quem eram os 
responsáveis pelos jornais. Como nosso objetivo era selecionar jornais cuja autoria fosse estudantil, realizamos a leitura do primeiro número dos 124 periódicos do período. Dessa leitura, alimentamos fichas de análise com dados obtidos dos periódicos redigidos por estudantes, tomando como ponto de partida as fichas de análise expostas por Nóvoa (2002) para construção do seu repertório analítico. Encontramos, nesse procedimento, 32 periódicos que indicavam explicitamente que haviam sigo escritos por estudantes.

Foi durante esse processo de leitura preliminar dos primeiros números dos jornais e de preenchimento das fichas que classificamos a tipologia das publicações (NÓVOA, 2002), isto é, verificamos a existência de dois tipos de periódicos escritos por estudantes: a "imprensa escolar", tal qual anunciada por Leonardo Arroyo (201 1); a "imprensa estudantil". António Nóvoa (2002) explicou que a tipologia permite uma apreensão global da imprensa, desde os temas mais presentes na investigação histórica em educação até os aspectos que não foram objeto de estudo sistemático. A tipologia é um primeiro esforço de interpretação da imprensa selecionada e fornece linhas orientadoras para análise. No caso da imprensa escrita por estudantes, a classificação das tipologias priorizou o local em que o estudante escreveu (dentro ou fora da escola).

A imprensa escolar era aquela redigida por estudantes dentro da escola, como uma atividade escolar. Por ser uma atividade solicitada na escola, havia a mediação, o direcionamento ou o cerceamento do adulto no processo. A escrita, nesses periódicos, não era, pois, autônoma. Como exemplo desse primeiro tipo, podemos citar o periódico $\bigcirc$ Aspirante: Periodico Litterario e Artístico dos alumnos do Lyceo de Artes e Officios (1881), que, no título, menciona seu vínculo com uma instituição de ensino.

A imprensa estudantil, por sua vez, era realizada por iniciativa dos estudantes, desvinculada da instituição de ensino que seus redatores frequentavam. Os alunos se reuniam em associações literárias, sem qualquer ligação com as instituições de ensino, para escreverem jornais de forma autônoma, o que tornava sua escrita relativamente livre. Por meio desses documentos, é possível analisar a escrita discente produzida sem a intervenção direta dos educadores. O periódico A ldea: Orgam do Club dos Estudantes (1888) é um exemplo desse tipo de periódico. $\bigcirc$ "Club dos Estudantes" era uma associação literária independente, formada por estudantes de algumas instituições de ensino secundário paranaense. 
Optamos, diante disso, por não utilizar a alcunha estabelecida por Leonardo Arroyo (201 1) de "imprensa escolar" para os jornais produzidos por estudantes, pois o termo limita o estudo aos jornais escritos por estudantes em alguma escola. Preferimos utilizar o termo "imprensa estudantil", pois ele considera o sujeito que escreveu (estudante) e não de onde escreveu (escola). Ao utilizar a noção teórica "imprensa estudantil", ampliamos a abrangência dos periódicos, pois podemos incluir todos os periódicos escritos por estudantes, independente de terem sido escritos dentro ou fora da escola. Alguns dos periódicos eram, portanto, estudantis e escolares e outros estudantis e não-escolares.

Essas tipologias não são meras classificações, mas implicam em distintas formas de análise desses documentos. É, pois, necessário considerar que o trato metodológico e analítico com um jornal estudantil deve ser distinto do trato com um jornal escolar. Para Bastos (2015), nos periódicos publicados nas instituições escolares, os alunos publicavam contribuições decorrentes de uma seleção prévia dos responsáveis e, devido a isso, deve-se considerar que "[...] tais escritas não expressam um pensamento autônomo, pois estão vinculados a uma instituição, que de alguma forma exerce controle e vigilância no que está sendo publicado" (BASTOS, 2015, p. 25). Dessa maneira, deve-se ter a consciência, ao analisar os jornais escolares, do papel e da presença do adulto no processo de escrita discente.

A imprensa estudantil não-escolar, por outro lado, caracteriza-se por ser um meio fundamentalmente informal ou não-formal de educar, pois "[...] engloba uma diversidade de formas de educação que não se pautam por lógicas e processos escolares" (NÓVOA, 2002, p. 26). Dessa forma, a imprensa estudantil não-escolar é um espaço educativo, em que os estudantes, a seu modo, educavam seus pares. Não se pode perder de vista, contudo, a influência da escola e a presença dos processos escolares nesse tipo de imprensa desvinculada da escola, já que, em muitos casos, para elaborar seus periódicos, os estudantes pautavam-se naquilo que era abordado no cotidiano escolar. 


\section{Mapeamento dos jornais estudantis: a produção periódica estudantil e juvenil oitocentista}

Após a descrição do processo de rastreamento dos periódicos estudantis na Hemeroteca Digital Brasileira, neste tópico, apresentamos o mapeamento dos jornais estudantis oitocentistas e algumas considerações, no que tange as suas datas e locais de publicação, seus títulos, e número de edições disponíveis. Esse exercício de mapear os periódicos nada tem de definitivo, mas pretende servir, antes, como um catálogo inicial desses documentos históricos nesse acervo específico. Nóvoa $(2002$, p. 18) iá havia nos alertado sobre o caráter transitório inerente à elaboração de repertórios: "Esse método de trabalho não nos colocou ao abrigo de falhas e omissões e, por isso, temos de acertar o caráter 'transitório' e 'incompleto' da investigação". Por isso, o mapeamento é provisório, pois consideramos que ele pode ser fomentado, à medida que avançarem os estudos acerca dos jornais estudantis na própria Hemeroteca Digital Brasileira e em outros acervos de periódicos brasileiros.

Organizamos os periódicos encontrados em dois quadros, de forma que em ambos constam o título, o local de publicação, a data e os números publicados. Priorizamos, nesta pesquisa, a questão temporal, haja vista um crescente aumento no número de periódicos encontrados. Isso justifica a organização dos jornais identificados em dois quadros: o primeiro contém os periódicos de 1840 a 1870; o segundo, os de 1880. 


\section{Quadro 1}

Título, local, ano de publicação e números disponíveis dos jornais estudantis das décadas de 1840 a 1870

\begin{tabular}{|c|c|c|c|c|}
\hline & Título & Local & Ano & $\begin{array}{l}\text { Número } \\
\text { disponível }\end{array}$ \\
\hline 1 & $\begin{array}{l}\text { Jornal de Instrucção e } \\
\text { Recreio }\end{array}$ & $\begin{array}{l}\text { São Luiz, } \\
\text { Maranhão }\end{array}$ & $1845 / 1846$ & $\begin{array}{l}1 \text { a } 23 \\
(1845) \\
24(1846)\end{array}$ \\
\hline 2 & $\begin{array}{l}\text { A voz da mocidade: } \\
\text { Periodico litterario, dou- } \\
\text { trinario e Moral }\end{array}$ & $\begin{array}{l}\text { Cachoeira } \\
\text { Bahia }\end{array}$ & 1850 & $\begin{array}{l}1,4,5,8, \\
9,10,11, \\
12,13, \\
14 \text { e } 15\end{array}$ \\
\hline 3 & $\begin{array}{l}\text { Murmurios Juvenis: } \\
\text { Jornal scientifico e litte- } \\
\text { rario publicado pela } \\
\text { Associação Amor à } \\
\text { Sciencia, estabelecida } \\
\text { no Collegio Brasileiro }\end{array}$ & São Paulo & 1859 & 1 \\
\hline 4 & $\begin{array}{l}\text { O trabalho escolástico: } \\
\text { Jornal litterario e recre- } \\
\text { ativo. Redigido por } \\
\text { alguns estudantes }\end{array}$ & Rio de Janeiro & 1860 & $2 e 3$ \\
\hline 5 & $\begin{array}{l}\text { O estudante: Periódico } \\
\text { critico e recreativo }\end{array}$ & $\begin{array}{lr}\text { Natal, } & \text { Rio } \\
\text { Grande } & \text { do } \\
\text { Norte } & \\
\end{array}$ & 1861 & 3 \\
\hline 6 & $\begin{array}{l}\text { A mocidade: Periodico } \\
\text { Litterario }\end{array}$ & $\begin{array}{l}\text { Rio de Janeiro, } \\
\text { Rio de Janeiro }\end{array}$ & 1862 & 1,2 e 3 \\
\hline 7 & $\begin{array}{l}\text { O estudante: Jornal litte- } \\
\text { rario e critico }\end{array}$ & $\begin{array}{l}\text { São Luiz, } \\
\text { Maranhão }\end{array}$ & 1870 & 1,2 e 3 \\
\hline
\end{tabular}




\section{Quadro 1}

Título, local, ano de publicação e números disponíveis dos jornais estudantis das décadas de 1840 a 1870 (continuação)

\begin{tabular}{|c|c|c|c|c|}
\hline & Título & Local & Ano & $\begin{array}{l}\text { Número } \\
\text { disponível }\end{array}$ \\
\hline 8 & O estudante & $\begin{array}{l}\text { Diamantina, } \\
\text { Minas Gerais }\end{array}$ & 1873 & $\begin{array}{ll}10, & 11 \\
12, & 18 \mathrm{e} \\
19 & \end{array}$ \\
\hline 9 & $\begin{array}{l}\text { A mocidade: jornal } \\
\text { litterario, critico e no- } \\
\text { ticioso. Redigido por } \\
\text { uma associação }\end{array}$ & $\begin{array}{l}\text { São Luiz, } \\
\text { Maranhão }\end{array}$ & $1875 / 1876$ & $\begin{array}{l}1 \quad \text { a o } \\
15(1875) \\
16 \text { ao } 29 \\
(1876)\end{array}$ \\
\hline 10 & $\begin{array}{l}\text { O Collegial: periodico } \\
\text { quinzenal - Orgão dos } \\
\text { Alumnos do Collegio } \\
\text { Briggs }\end{array}$ & $\begin{array}{l}\text { Nictheroy, Rio } \\
\text { de Janeiro }\end{array}$ & 1876 & 2 \\
\hline 11 & $\begin{array}{l}\text { Revista Juvenil: jornal } \\
\text { litterario, critico e no- } \\
\text { ticioso. Redigido por } \\
\text { uma associação }\end{array}$ & Maranhão & $1876 / 1877$ & $\begin{array}{lll}1 & \text { ao } & 4 \\
(1876) & \\
5 & \text { ao } & 12 \\
1 & 1877 & \end{array}$ \\
\hline 12 & $\begin{array}{l}\text { Echo Litterario: } \\
\text { Orgão da Mocidade } \\
\text { Escolastica }\end{array}$ & Rio de Janeiro & 1877 & 2 \\
\hline 13 & $\begin{array}{l}\text { A Luz: propriedade de } \\
\text { uma associação de } \\
\text { estudantes }\end{array}$ & $\begin{array}{l}\text { A r a c a i ú, } \\
\text { Sergipe }\end{array}$ & $\begin{array}{l}1877 \\
1880\end{array}$ & $\begin{array}{l}5(1877) \\
2(1880) \\
\end{array}$ \\
\hline 14 & $\begin{array}{l}\text { A escola: Jornal critico e } \\
\text { litterario }\end{array}$ & Maranhão & $1878 / 1902$ & $\begin{array}{l}1,2 \text { e } 3 \\
(1878) \\
1(1902)\end{array}$ \\
\hline
\end{tabular}




\section{Quadro 1}

Título, local, ano de publicação e números disponíveis dos jornais estudantis das décadas de 1840 a 1870 (continuação)

\begin{tabular}{|c|l|l|l|l|}
\hline \multicolumn{1}{|c|}{ Título } & \multicolumn{1}{|c|}{ Local } & \multicolumn{1}{c|}{ Ano } & $\begin{array}{l}\text { Nú m e ro } \\
\text { disponível }\end{array}$ \\
\hline 15 & $\begin{array}{l}\text { Mirim: órgão do Club } \\
\text { dos Estudantes, publi- } \\
\text { cação mensal }\end{array}$ & $\begin{array}{l}\text { B rag a n ça, } \\
\text { São Paulo }\end{array}$ & $1878 / 1879$ & $\begin{array}{l}15(1878) \\
21(1879)\end{array}$ \\
\hline 16 & $\begin{array}{l}\text { O reverbero: Orgam } \\
\text { do club dos estudantes }\end{array}$ & $\begin{array}{l}\text { C u r i i i b a a } \\
\text { Paraná }\end{array}$ & 1879 & 1 \\
\hline
\end{tabular}

Fonte: Quadro realizado pela autora a partir da pesquisa no acervo digital da Hemeroteca Digital Brasileira.

No Quadro 1, em que listamos os periódicos publicados nas décadas de 1840 a 1870, constata-se a existência de 16 periódicos publicados em diversas províncias brasileiras durante esse período de quarenta anos. No quadro 2, listamos outros 16 jornais publicados apenas na década de 1880. De acordo com o levantamento feito no acervo da Hemeroteca, a soma dos periódicos estudantis publicados entre 1840 e 1880 totaliza 32 periódicos.

\section{Quadro 2}

Título, local, ano de publicação e números disponíveis dos jornais estudantis da década de 1880

\begin{tabular}{|c|l|l|l|l|}
\hline & Título & Local & Ano & $\begin{array}{l}\text { Nú mero } \\
\text { disponível }\end{array}$ \\
\hline \multirow{1}{*}{1} & $\begin{array}{l}\text { Rio Branco: órgão lit- } \\
\text { terario, scientifico e } \\
\text { histórico da Sociedade } \\
\text { Minerva e dos alumnos } \\
\text { do Collegio São Carlos }\end{array}$ & $\begin{array}{l}\text { Rezende, Rio } \\
\text { de Janeiro }\end{array}$ & $1881 / 1882$ & $1(1881)$ \\
$1(1882)$
\end{tabular}




\section{Quadro 2}

Título, local, ano de publicação e números disponíveis dos jornais estudantis da década de 1880 (continuação)

\begin{tabular}{|c|c|c|c|c|}
\hline & Título & Local & Ano & $\begin{array}{l}\text { Núm e ro } \\
\text { disponível }\end{array}$ \\
\hline 2 & $\begin{array}{l}\text { A Ventarola: periodico } \\
\text { dos Alumnos no Lyceu } \\
\text { de Artes e Officios }\end{array}$ & Rio de Janeiro & 1881 & 1,2 e 4 \\
\hline 3 & $\begin{array}{l}\text { O aspirante: Periodico } \\
\text { Litterario e Artístico dos } \\
\text { alumnos do Lyceo de } \\
\text { Artes e Officios }\end{array}$ & Rio de Janeiro & $1881 / 1882$ & $\begin{array}{l}1 \text { ao } 12 \\
(1881) \\
13 \text { e } 14 \\
(1882)\end{array}$ \\
\hline 4 & $\begin{array}{l}\text { Estudante: } \\
\text { Semanario Critico e } \\
\text { Litterario }\end{array}$ & Rio de Janeiro & 1881 & 1 \\
\hline 5 & $\begin{array}{l}\text { Labarum: Orgão da } \\
\text { Sociedade Litterario } \\
\text { do Atheneu Mineiro - } \\
\text { Obreiros do Futuro } \\
\end{array}$ & $\begin{array}{l}\text { Juiz de Fora, } \\
\text { Minas Gerais }\end{array}$ & 1882 & 1,6 e 7 \\
\hline 6 & $\begin{array}{l}\text { Progresso Recreativo: } \\
\text { Periódico Litterario, } \\
\text { Scientifico e Noticioso, } \\
\text { do Collegio Naval } \\
\end{array}$ & Rio de Janeiro & 1882 & 2 \\
\hline 7 & $\begin{array}{l}\text { A idéa: Propriedade } \\
\text { dos alumnos do } \\
\text { Collégio S. João }\end{array}$ & $\begin{array}{l}P \text { e n e d o } \\
\text { Alagoas }\end{array}$ & $1883 / 1885$ & $\begin{array}{l}1(1883) \\
8(1885) \\
\end{array}$ \\
\hline 8 & $\begin{array}{l}\text { A escola: sob a direção } \\
\text { da Sociedade Recreio } \\
\text { Scientifico no Collegio } \\
\text { Bom Jesus }\end{array}$ & $\begin{array}{l}\text { Ma c e i ó, } \\
\text { Alagoas }\end{array}$ & $\begin{array}{l}1883 / 1884 \\
/ 1885\end{array}$ & \begin{tabular}{|lcc}
1 & $e$ & 3 \\
$(1883)$ & \\
1 & $e$ & 3 \\
$(1884)$ & \\
$2(1885)$ \\
\end{tabular} \\
\hline
\end{tabular}




\section{Quadro 2}

Título, local, ano de publicação e números disponíveis dos jornais estudantis da década de 1880 (continuação)

\begin{tabular}{|c|c|c|c|c|}
\hline & Título & Local & Ano & $\begin{array}{l}\text { Nú m e ro } \\
\text { disponível }\end{array}$ \\
\hline 9 & $\begin{array}{l}\text { A mocidade: orgam } \\
\text { do Club Amante do } \\
\text { Progresso }\end{array}$ & $\begin{array}{l}\text { C u ri i i b a, } \\
\text { Paraná }\end{array}$ & 1883 & 3 \\
\hline 10 & $\begin{array}{l}\text { Alvorada: Orgam do } \\
\text { Collegio Conceição }\end{array}$ & $\begin{array}{l}\text { São João d'El } \\
\text { Rei, Minas } \\
\text { Gerais }\end{array}$ & 1886 & 2 \\
\hline 11 & $\begin{array}{l}\text { estudo: Folha } \\
\text { Quinzenal - Orgam do } \\
\text { Club Litterario "Diegues } \\
\text { Junior". Fundado entre } \\
\text { os alunos do Instituto } \\
\text { "19 de Abril" }\end{array}$ & $\begin{array}{l}R \text { e c if e } \\
\text { Pernambuco }\end{array}$ & 1886 & $\begin{array}{l}2,3,4,5 \\
\text { e } 8\end{array}$ \\
\hline 12 & $\begin{array}{l}\text { A opinião: Orgão de } \\
\text { Estudantes }\end{array}$ & $\begin{array}{l}\text { Curi ti ba, } \\
\text { Paraná }\end{array}$ & 1887 & 1 ao 8 \\
\hline \multirow[t]{2}{*}{13} & \multirow[t]{2}{*}{$\begin{array}{l}\text { Chrysalida: Jornal do } \\
\text { Collegio Santa Thereza } \\
\text { - Publicação Quinzenal }\end{array}$} & \multirow[t]{2}{*}{ Rio de Janeiro } & \multirow[t]{2}{*}{$\begin{array}{l}1887 / 1888 \\
/ 1889\end{array}$} & $\begin{array}{l}2,3,4 \text { e } 5 \\
(1887) \\
6,8,9, \\
15, \quad 16, \\
17, \quad 18, \\
19, \quad 20, \\
25, \quad 29 \\
11888)\end{array}$ \\
\hline & & & & 32 (1889) \\
\hline
\end{tabular}




\section{Quadro 2}

Título, local, ano de publicação e números disponíveis dos jornais estudantis da década de 1880 (continuação)

\begin{tabular}{|c|c|c|c|c|}
\hline & Título & Local & Ano & $\begin{array}{l}\text { Núm e ro } \\
\text { disponível }\end{array}$ \\
\hline 14 & $\begin{array}{l}\text { A União: órgão dos alu- } \\
\text { mnos da Escola Central }\end{array}$ & $\begin{array}{l}\text { Ma c e i ó, } \\
\text { Alagoas }\end{array}$ & $\begin{array}{l}1888 / \\
1889\end{array}$ & $\begin{array}{l}8 \text { e } 18 \\
(1888) \\
39(1889)\end{array}$ \\
\hline 15 & $\begin{array}{l}\text { A idea: Orgam do Club } \\
\text { dos Estudantes }\end{array}$ & $\begin{array}{l}\text { Curitiba, } \\
\text { Paraná }\end{array}$ & $1888 / 1899$ & $\begin{array}{lll}1 & \text { ao } & 6 \\
1 & 1888) \\
7 & \text { ao } & 17 \\
1 & 1899 & \end{array}$ \\
\hline 16 & $\begin{array}{l}\text { Aurora Atheniense: } \\
\text { Revista Mensal dos } \\
\text { Estudantes do Collegio } \\
\text { Atheneu Bahiano }\end{array}$ & $\begin{array}{l}\text { Salvador, } \\
\text { Bahia }\end{array}$ & 1888 & 3 \\
\hline
\end{tabular}

Fonte: Quadro realizado pela autora a partir da pesquisa no acervo digital da Hemeroteca Digital Brasileira.

Com os dados organizados nos quadros anteriores, foi possível tecer algumas considerações preliminares e caracterizar os periódicos estudantis publicados durante o regime imperial quanto ao período e locais de publicação, quanto ao título e, por fim, quanto à quantidade de números publicados e/ou quantidade de números disponibilizados no acerco da Hemeroteca.

\section{Quanto ao período de publicação}

No que diz respeito ao período das publicações desses jornais, os quadros elucidam que a produção periódica estudantil aconteceu entre meados da década de 1840 até o final do regime imperial, isto é, final da década de 1880. No primeiro quadro, nota-se uma tendência de crescimento na publicação de periódicos pelos estudantes brasileiros até a década de 1870, já 
que a produção foi crescente, aumentando década a década. $\bigcirc$ segundo evidencia que a década de 1880 foi o momento em que a prática de publicar jornais entre a classe estudantil se consolidou. No quadro a seguir (Quadro 3), destacamos o número de produtos por década, facilitando a visualização da tendência de crescimento e consolidação da prática.

Quadro 3

Número de produções por década

\begin{tabular}{|l|l|}
\hline Décadas das publicações & Número de produtos \\
\hline 1840 & 1 \\
\hline 1850 & 2 \\
\hline 1860 & 3 \\
\hline 1870 & 10 \\
\hline 1880 & 16 \\
\hline
\end{tabular}

Fonte: Elaborado pela autora, com base nos levantamentos da produção periódica da juventude brasileira.

Os jornais publicados em quatro décadas, de 1840 a 1870, somam 16. Foram publicações tímidas e crescentes até a década de 1860 e, em seguida, houve um aumento significativo na década de 1870, confirmando a tendência de crescimento nas publicações. $\bigcirc$ que chama a atenção é que a quantidade de produtos publicados em quatro décadas foi a mesma publicada em apenas uma, isto é, na década de 1880. O considerável aumento ocorrido na década de 1870 demonstra que esse foi o momento em que a produção de jornais entre os discentes se popularizou, tornando-se, de fato, um movimento da classe estudantil, e esse movimento de produção e leitura de jornais consolidou-se enquanto prática discente na década de 1880. Baseados nessas constatações, questionamos sobre quais foram os condicionantes históricos no Brasil que justificam o aumento das produções desse gênero, mormente nas últimas décadas do Império.

O contexto histórico oitocentista é elucidativo dos motivos que levaram à realização de tal empreendimento. A necessidade de construção da nação e da nacionalidade brasileira decorrente do processo de Independência do Brasil é, para nós, norteadora na compreensão do engajamento da juventude 
na produção periódica. Na busca por firmar-se enquanto nação autônoma, urgia ao Estado brasileiro o ordenamento de um aparato que the assegurasse sustentação. A imprensa, a educação e a literatura foram ferramentas fundamentais utilizadas para formação de uma consciência nacional entre a população.

A instrução e a literatura estavam em evidência por serem, conforme destacamos, ferramentas para a sustentação e consolidação da nação brasileira: a instrução, por meio da formação de sujeitos instruídos intelectual e moralmente, capazes de uma atuação coerente e consciente na pátria; a literatura, mormente a romântica, por meio da criação de textos originais brasileiros, com forte teor patriótico e ufanista, que davam visibilidade e enalteciam as paisagens e o povo brasileiro, criando símbolos e uma memória nacional.

Sobre a instrução, Machado (2010, p. 154) explica que foi nesse século que "[...] a instrução pública se tornou objeto de debates por parte dos políticos e da sociedade civil, propagando-se com imperiosa força social". Frente ao fundamental papel a ela atribuído, muitos foram os esforços para a organização e a institucionalização da instrução pública, que foram traduzidos em inúmeras leis educacionais e projetos de lei que foram engavetados 16 Sublinhamos, sobretudo, o papel da imprensa na formação dessa consciência nacional. Os periódicos do período foram instrumentos patrióticos, pois davam visibilidade, nas notícias, artigos, editoriais e na literatura, às questões nacionais, seja em suas qualidades ou em seus problemas. Neles, não mais priorizavam assuntos ligados à metrópole e aos países estrangeiros; atuavam como formadores de opiniões; consolidavam a língua nacional, elemento simbólico que caracterizava uma pátria e um povo; disseminava dos padrões de comportamento adequados à nação, isto é, moralizava os súditos; entre outros.

Além disso, por ser uma "empresa educativa" (PALLARES-BURKE, 1998), isto é, por ter caráter essencialmente formativo, a imprensa foi posta a serviço de grupos que disputavam hegemonia política com seus distintos projetos para construção da nação brasileira e de seu povo. Ela tornou-se arena de debate, campo de disputa de poder dos mais distintos grupos que buscavam supremacia para a construção do Brasil.

Sobretudo após a década de 1870, a imprensa registrou as inúmeras transformações daquele agitado contexto pré-Proclamação da República e foi porta-voz do posicionamento heterogêneo de muitos grupos sobre essas 
transformações. Registrou os discursos dos abolicionistas e dos escravocratas; dos republicanistas e dos monarquistas; dos anticlericalistas e dos ultramontanos, além de questões subjacentes a esses discursos, como as relacionadas à industrialização, à agricultura, à imigração, ao exército, à educação, entre muitos outros. $\bigcirc$ contexto histórico foi propício, portanto, para a multiplicação de jornais que representavam distintos grupos, coroando a imprensa como principal meio de legitimação da nação brasileira e formação do povo brasileiro.

Os jovens estudantes inseridos nesse processo não ficaram alheios e demonstraram-se atentos àquilo que os cercava e, reconhecendo a importância da imprensa como meio de educar e de expressar o posicionamento da classe estudantil diante das questões candentes do período, inseriram-se no processo criando seus próprios periódicos. Eles acompanharam o ritmo de ebulição nacional, sobretudo, após a década de 1870, criando um jornalismo tipicamente estudantil, em que se expressavam e cultivavam ciências e letras, em diferentes locais do país.

\section{Quanto aos locais de publicação}

Outro aspecto observado nos jornais levantados relaciona-se aos locais de publicação. No Quadro 4, listamos as províncias, as cidades, e o número de jornais publicados em cada uma delas:

\section{Quadro 4}

Províncias e cidades onde os jornais foram produzidos

\begin{tabular}{|l|l|l|}
\hline \multicolumn{1}{|c|}{ Província } & \multicolumn{1}{|c|}{ Cidade } & Número de produções \\
\hline \multirow{2}{*}{ Alagoas } & Maceió (Capital) & 2 \\
\cline { 2 - 3 } & Penedo & 1 \\
\hline \multicolumn{2}{|c|}{} & Total: 3 \\
\hline \multirow{2}{*}{ Bahia } & Salvador (Capital) & 1 \\
\cline { 2 - 3 } & Cachoeira & 1 \\
\hline
\end{tabular}


Quadro 4

Províncias e cidades onde os jornais foram produzidos (continuação)

\begin{tabular}{|c|c|c|}
\hline \multirow[t]{2}{*}{ Província } & Cidade & Número de produções \\
\hline & & Total: 2 \\
\hline \multirow[t]{2}{*}{ Maranhão } & $\begin{array}{ll}\text { São } & \text { Luiz } \\
\text { (Capital) } & \end{array}$ & 5 \\
\hline & & Total: 5 \\
\hline \multirow{2}{*}{ Pernambuco } & Recife (Capital) & 1 \\
\hline & & Total: 1 \\
\hline \multirow[t]{2}{*}{$\begin{array}{l}\text { Rio Grande do } \\
\text { Norte } \\
\end{array}$} & Natal (Capital) & 1 \\
\hline & & Total: 1 \\
\hline \multirow[t]{2}{*}{ Sergipe } & Aracajú (Capital) & 1 \\
\hline & & Total: 1 \\
\hline \multirow{3}{*}{ Minas Gerais } & Diamantina & 1 \\
\hline & Juiz de Fora & 1 \\
\hline & São João d'El Rei & 1 \\
\hline \multirow{4}{*}{ Rio de Janeiro } & & Total: 3 \\
\hline & $\begin{array}{l}\text { Rio de Janeiro } \\
\text { (Capital do } \\
\text { Império) }\end{array}$ & 8 \\
\hline & $\begin{array}{l}\text { Niterói (Capital } \\
\text { da Província) }\end{array}$ & 1 \\
\hline & Rezende & 1 \\
\hline \multirow{3}{*}{ São Paulo } & & Total: 10 \\
\hline & $\begin{array}{l}\text { São Paulo } \\
\text { (Capital) }\end{array}$ & 1 \\
\hline & Bragança & 1 \\
\hline & Total: 2 \\
\hline
\end{tabular}




\section{Quadro 4}

Províncias e cidades onde os jornais foram produzidos (continuação)

\begin{tabular}{|l|l|l|}
\hline \multicolumn{1}{|c|}{ Província } & \multicolumn{1}{c|}{ Cidade } & Número de produções \\
\hline Paraná & Curitiba (Capital) & 4 \\
\hline \multicolumn{2}{|l}{} & Total: 4 \\
\hline Total & 32 \\
\hline
\end{tabular}

Fonte: Elaborado pela autora, com base nos levantamentos da produção periódica da juventude brasileira

A necessidade de agir coordenado gera na sociedade uma determinada $\bigcirc$ Quadro mostra que foram publicados jornais estudantis em dez províncias brasileiras. Dessas dez províncias, Rio de Janeiro, Maranhão e Paraná tiveram maior número de produtos. No entanto, ocorreu um predomínio de publicações na província do Rio de Janeiro, que abrigava o município neutro e a capital do país, o que demonstra o desenvolvimento material, cultural e intelectual dessa província, além de ser um local de criação e disseminação de modelos e práticas.

$\bigcirc$ Quadro 5 ilustra, além disso, a importância das capitais como "modelo a ser seguido", ou seja, como referência para as demais cidades da província. Constatamos que, dentre os 32 jornais da nossa amostra, 24 jornais foram publicados nas capitais provinciais, ou $75 \%$ deles. De acordo com esta pesquisa, quase que a totalidade das províncias que publicaram periódicos estudantis tiveram produtos em suas capitais. Apenas uma exceção foi observada na província de Minas Gerais, pois nela não encontramos ocorrências de produtos desse tipo em sua capital, Ouro Preto.

A província do Rio de Janeiro apresenta uma singularidade. Naquele período, a sua capital era a cidade de Nicteroy e, ainda que fosse a capital, produziu apenas um jornal. No entanto, nessa província, situava-se a capital do Império, isto é, a cidade do Rio de Janeiro, município neutro, que foi sede do governo do Império de Portugal e da corte portuguesa, nos anos de 1808 até 1822, quando foi declarada sua independência de Portugal. Desde então, o Rio de Janeiro tornou-se a cidade mais desenvolvida do país, nos aspectos estruturais, culturais, políticos, econômicos, educacionais, além de dispor dos primeiros tipógrafos do país com a instalação da Imprensa Régia. Por esse 
motivo, a capital do Império era um polo, não somente dessa província, mas também de todo o Brasil, o que pode justificar o avanço do número de produções de jornais estudantis nessa província.

Os jornais publicados fora das capitais somaram 25\% de nossa amostra. A produção de periódicos estudantis fora da capital demonstra que a prática de escrita de jornais por discentes tornava-se, cada vez mais, uma tendência da época e adquiria status de movimento nacional dos estudantes, não somente nos principais polos regionais, mas também fora deles.

Para nós, essa prática nas capitais serviu de modelo para as demais cidades das províncias. Nos periódicos, é possível encontrar alguns indicativos de uma possível circulação dos jornais da capital nas províncias. Pode-se verificar, no cabeçalho de alguns deles, que os estudantes estipulavam um valor de venda para assinantes do local em que o jornal era produzido (capital) e outro valor para os assinantes de outras localidades (fora da capital). Esse poderia ser um dos meios de circulação dos periódicos nas cidades do interior das províncias que, após terem contato com eles, adotavam-nos como exemplo, referência para a produção de jornais. Outra conduta que pode ter contribuído para a interiorização do movimento de publicação de jornais estudantis foi a 20 prática da troca de jornais entre redações, isto é, uma redação enviava para outra a edição mais recente. Com essa conduta colocava-se em circulação os periódicos produzidos tanto na capital quanto nos lugares mais remotos, o que contribuía para a propagação da prática.

\section{Quanto ao título}

Os títulos dos periódicos que compõem o mapeamento fornecem pistas acerca dos conteúdos que foram neles privilegiados. Acreditamos que o título é escolhido pelos seus responsáveis para servir como apresentação inicial ao leitor, ou seja, como uma vitrine, aquilo que o identifica, que representa genericamente os principais assuntos abordados naquele jornal.

Em especial, nos complementos de título, os redatores procuravam dar ao leitor uma ideia geral acerca do periódico, no que tangia à sua filiação, ao grupo a que pertencia, à periodicidade do jornal ou aos principais assuntos que eram abordados. Observamos que a literatura foi um assunto que apareceu em boa parte dos complementos de títulos dos jornais que compõem o 
quadro. Dentre os 32 títulos, 15 ou 47\% deles apresentaram o termo "litterario" ou "litteratura" em seus complementos de título, o que indica a prioridade da literatura nos textos desses periódicos. É válido acrescentar que, mesmo os jornais que não denunciavam no título que eram jornais literários, veiculavam, em seu interior, algum texto literário.

Entendemos que, dentre os muitos motivos e influências que podem ter contribuído para que os estudantes secundaristas elegessem a literatura como prioridade em seus jornais, duas causas foram fundamentais para essa escolha: o ensino essencialmente humanístico que recebiam nas instituições de ensino secundário e nas aulas avulsas que frequentavam; e a popularidade que a literatura adquiriu naquele período como instrumento de nacionalização e de patriotismo, sobretudo com os textos publicados na imprensa vinculados ao movimento literário do Romantismo.

Sobre o tipo de ensino que recebiam nas instituições de ensino secundário, Haidar (1972) explicou que o esse nível de ensino se destinava precipuamente ao preparo dos candidatos às escolas superiores do Império. Esses candidatos seriam os futuros dirigentes a assumirem os altos postos da burocracia nacional. Devido a isso, "[...] em todo o país, com um ou outro acrescentamento, com uma outra lacuna, reproduzia em seu currículo o conjunto de disciplinas fixadas pelo Centro para os exames de ingresso nas Academias" (HAIDAR, 1972, p. 19). Desse modo, o currículo tinha caráter humanístico e literário em consonância com as matérias exigidas nos exames gerais para ingresso nas universidades. Mesmo no final do regime imperial, em que se discutia a dualidade da função desse nível de ensino instigada pelo cientificismo positivo (deveria ser profissionalizante ou deveria preparar unicamente para o ingresso nas universidades, primando pelos estudos clássicos?), prevaleceu o currículo com caráter humanístico e literário, com vistas ao ensino superior.

No que concerne à popularização da literatura, no século XIX, ocorreu uma efervescência literária brasileira, sobretudo por meio do Romantismo. José Veríssimo explicou, em seu conhecido livro História da Literatura Brasileira (1915), que foi no período conhecido como Romantismo (cuja presença mais marcante esteve entre 1830 e 1870) que a literatura no Brasil começou a ser, de fato, escrita não mais nos moldes da literatura portuguesa, o que significou que o país alcançou a emancipação literária de Portugal. No período pós-Independência (1822), o Brasil, buscando legitimar-se enquanto nação autônoma, 
colocou a literatura a serviço da construção do sentimento de nação e de amor à pátria. A literatura romântica, ao enaltecer a paisagem brasileira e o seu povo, dava destaque às questões nacionais, incutindo no povo o orgulho e o amor à pátria tão necessários à consolidação da nação brasileira.

Data desse período a publicação dos jornais literários. Isso significa que o principal veículo de publicação da literatura naquele momento era a imprensa. A autora Arnt (1990) explicou que o jornalismo literário no Brasil foi particularmente importante, pois o movimento editorial de livros era fraco. Por isso, praticamente todos os literatos passaram pelos jornais, como Raul Pompéia, Aluísio de Azevedo, Machado de Assis. Esse jornalismo deixou um legado para a cultura brasileira, segundo a autora, pois foi publicado um elevado número de obras literárias. Por meio dos jornais literários, a literatura circulou e se popularizou, ganhando estima do público leitor brasileiro. Os estudantes, que viviam esse período de efervescência literária nos jornais, inseriram-se nesse processo fazendo dos seus jornais um espaço de publicação de seus próprios textos literários. Assim, o jornal foi o melhor caminho encontrado pelos estudantes secundaristas para divulgarem a sua literatura, a exemplo do que faziam os autores do período.

22 Outro aspecto observado nos títulos que consideramos relevante é o número de jornais que vincularam sua produção periódica a uma associação literária. Dos 32 periódicos encontrados, 11 declaram-se, no título, como pertencentes a uma associação literária. Isso significa que os jornais eram produtos dos membros/sócios dessas associações. As associações literárias eram locais em que os estudantes se reuniam para estudar e produzir ciência e literatura. Eram, portanto, espaços de produção e compartilhamento coletivo de ideias entre os discentes, seja nas sessões da associação, em que se reuniam pessoalmente para debater temas variados, ou por meio da elaboração de periódicos que expressavam e registravam publicamente o pensamento dessa classe.

Milena da Silveira Pereira (2015) debruçou-se sobre o despertar do gosto da intelectualidade brasileira. Essa autora explicou que foi sobretudo no século XIX que ocorreram tentativas de criação de associações. Após a Independência (1822), a nação brasileira começou a trilhar caminho próprio, favorecendo a criação de sociedades de caráter literário no país. As agremiações fundadas nesse período, preocuparam-se com os destinos da nacionalidade brasileira, tentando influir no cenário social e cultural do país. 
Pereira (2016) acrescentou que um dos instrumentos para forjar a nacionalidade brasileira foi o fomento e abertura de espaço para as associações literárias.

Especialmente, após a abdicação de D. Pedro I (1831), o clima de agitações, revoltas, e afirmações patrióticas e nacionalistas tomou conta do país. Data desse período o surgimento de uma lista incontável de associações que demonstravam o desejo de criar um senso de coletividade, espírito público e o interesse em promover áreas como a instrução, a ciência, a indústria, o comércio, a música e belas-artes. Os letrados acreditavam que um esforço coletivo levaria ao desenvolvimento do país. Concomitante a notabilidade adquirida pela literatura, surgiram associações de cunho literário que, segundo Pereira (2015), foram as mais acaloradas na defesa do "espírito associativo" e de como poderiam colaborar para a afirmação e a promoção da literatura brasileira. Assim, o espírito coletivo tornou-se uma tradição entre os letrados brasileiros.

Essa autora destaca o papel da imprensa para essas agremiações, pois uma das principais características das sociedades literárias do século XIX era a produção de periódicos. Para ela, a imprensa era instrumento de manutenção da prática de associação dos letrados da época, pois, por meio dos jornais, tornavam-se públicos os escritos dos letrados, isto é, a produção dos letrados saía do restrito meio em que havia sido criada (PEREIRA, 2015).

Com base nos pressupostos de Pereira (2015), entendemos que foi decorrente dessa tradição dos letrados brasileiros de se associarem que os estudantes secundaristas se orientavam para criar suas próprias associações. Partiam da premissa de que a união de suas forças possibilitava sustentar uma causa. Eles colocavam-se como responsáveis por divulgar a cultura letrada, preenchendo uma lacuna de materiais de leitura para essa faixa etária. Ao tornarem público, pelo jornal, o resultado daquilo que debatiam nas associações, esses estudantes demonstravam o interesse em posicionarem-se frente às questões de seu tempo e de disseminavam a cultura letrada.

\section{Quanto à quantidade de números publicados e / ou disponibilizados no acervo digital}

A última coluna do Quadro 1 e 2 evidencia a quantidade de números publicados em cada periódico estudantil e/ou a disponibilidade dos 
números dos periódicos estudantis no site da Hemeroteca, isto é, quantos e quais números dos periódicos encontrados estão disponibilizados no acervo da Hemeroteca. Esse ponto deve ser considerado no trato com esse tipo de produção periódica, pois revela elementos sobre a conservação e arquivamento desses documentos junto aos acervos documentais brasileiros e, além disso, sobre as possíveis dificuldades dos alunos daquele período histórico em sustentar um jornal estudantil.

Os Quadros 1 e 2 mostram que, dos 32 jornais, apenas seis Vornal de Instrucção e Recreio, A Mocidade e Revista Juvenil, todos Maranhão; $O$ Aspirante, do Rio de Janeiro; A Opinião e A ldea, do Paraná, não têm números faltando, ou seja, tiveram seus números conservados, sem interrupções por perda ou falta de conservação. Não é possível identificar se os últimos números disponibilizados no acerco digital foram, de fato, o último número do jornal, pois existe a possibilidade de que os jornais tenham continuado seu trabalho, mas a biblioteca não tenha recebido os números subsequentes, caso eles tenham existido.

Os seis jornais supracitados possuem uma quantidade suficientemente longa de números publicados, isto é, uma série longa de análise (ARNAUT DE 24 TOLEDO; SKALINSKY JUNIOR, 2012). Arnaut de Toledo e Skalinsky Junior (2012) explicam que selecionar jornais que possuem uma série longa de análise ajuda a garantir interpretações que não sejam apenas pontuais, mas que tornem possível a constituição de unidades de análise generalizáveis. Dessa maneira, é possível uma apreensão das continuidades ou descontinuidades do periódico.

Por meio da quantidade de números publicados presentes na última coluna do Quadro 1 e 2, tem-se uma noção das dificuldades encontradas pelos estudantes no período, já que, na maioria deles, a duração dos periódicos foi efêmera. Sustentar um jornal por alguns meses era uma tarefa difícil e onerosa para os estudantes. As dificuldades enfrentadas eram, sobretudo, monetárias. Encontrar leitores que pagassem as mensalidades para financiar um periódico estudantil era um desafio. Os redatores frequentemente faziam apelo aos leitores para que aderissem à causa dos estudantes em publicar periódicos e honrassem com o pagamento das mensalidades, o que demonstra que esse era um dos seus principais obstáculos.

Para além dos seis jornais que possuíam todos os números disponibilizados na Hemeroteca, todos os outros periódicos do quadro 1 têm poucos 
números publicados (dez jornais, por exemplo, têm apenas um número disponibilizado na Hemeroteca) e a maior parte deles têm números faltando, o que evidencia a falta de conservação e arquivamento desses documentos históricos. Exemplo disso é o jornal Chrysalida, do Rio de Janeiro, que possui uma série longa de análise ( 16 números disponíveis), mas com edições perdidas, o que não permite uma análise sequenciada desses periódicos. $\bigcirc$ último número publicado de Chrysalida foi o 32, o que significa que teve, no mínimo, 32 números publicados. Contudo, dos 32 números, apenas temos acesso a metade deles, pois os demais não foram disponibilizados.

\section{Considerações Finais}

Por meio deste texto, compartilhamos os resultados de uma investigação e mapeamento de jornais estudantis publicados durante o regime imperial brasileiro, que foram disponibilizados na Hemeroteca Digital da Biblioteca Nacional. Os dados quantitativos analisados neste artigo revelam, pelo contingente de periódicos publicados, o comprometimento da mocidade estudiosa com a produção de jornais que tornassem públicos os seus ideais e posicionamentos, fazendo dessa prática um verdadeiro movimento estudantil de caráter nacional. A amplitude da prática dos discentes para elaborar jornais não pode ser ignorada, pois se constitui em rico material para pesquisas em História da Educação. De maneira específica, a produção estudantil pode enriquecer os estudos sobre a história dos estudantes, história da adolescência e da juventude, história dos impressos discentes, história das instituições escolares, entre outros.

Para além dos dados quantitativos, esses periódicos evidenciam que a classe estudantil do período imperial era consciente e engajada com as questões de seu período, sobretudo, com a causa da instrução. Eles tinham muito a dizer sobre a educação que recebiam. Esses documentos, quando visitados por pesquisadores, podem revelar uma perspectiva histórica sobre a educação imperial, distinta daquelas oferecidas pelas fontes comumente utilizadas pela historiografia da educação do Império, como as leis e os decretos, os documentos das instituições escolares ou os periódicos pedagógicos. Sublinham a perspectiva e as reivindicações da própria classe estudantil sobre sua educação, o que nos permite uma aproximação com questões do cotidiano dos 
alunos e alunas secundaristas. Destacamos que o acesso a esse nível de ensino era restrito a estudantes que não precisavam trabalhar e que poderiam se voltar integralmente à ampliação de seu repertório cultural e a uma cultura desinteressada.

Além disso, os estudantes priorizaram a elaboração de jornais literários. Em uma rápida visita aos periódicos que compõem o mapeamento, é possível observar o espaço oferecido pelos estudantes para a publicação de literatura. Devido à predileção pela publicação de jornais literários, empenharam-se em escrever uma literatura original e autoral, o que permite afirmar que os jornais estudantis foram importantes materiais de leitura literária para a mocidade brasileira oitocentista. Por isso, um olhar atento à literatura produzida pelos estudantes nesses periódicos pode contribuir para a historiografia da literatura infanto-juvenil brasileira, já que os jovens brasileiros do regime imperial liam literatura por meio de seus periódicos.

\section{Notas}

1 Este artigo é parte dos resultados da pesquisa de tese de doutoramento intitulada Pelos estudantes e para os estudantes: a instrução e a literatura nos periódicos estudantis brasileiros (1870-1880) (2020), realizada no Programa de Pós-Graduação em Educação (UEM). Vincula-se aos projetos de pesquisa do Grupo de Estudos e Pesquisa em História da Educação, Intelectuais e Instituições Escolares.

2 Nossas fichas de análise são compostas por título, complemento de título, locais e datas de publicação, número de página, valor das mensalidades, menção de responsabilidade lassociação a que pertenciam, nome dos diretores, redatores e principais colaboradores, instituição de ensino que os estudantes frequentavam), objetivos, colunas fixas e principais temáticas.

3 Machado (2010) cita que as leis para a instrução pública sancionadas no período imperial foram: a Constituição (1 824); a Lei das Primeiras Letras (1827); o Ato Adicional a Constituição (1834); a Reforma Couto Ferraz (1 854); e o Decreto de Leôncio de Carvalho (1879).

4 Dentre os projetos para instrução pública que não tiveram andamento na Assembleia Legislativa está o Projeto/Parecer sobre a educação de Rui Barbosa, resultado do minucioso estudo desse autor sobre o Decreto de Leôncio de Carvalho. Seus Pareceres revelam, além do posicionamento desse autor frente à educação, um rico panorama da educação do século XIX (MACHADO, 2005; MACHADO; MÉLO, 2007). 


\section{Referências}

A IDEA, Curityba, Paraná, n. 1-6, 1888.

A IDEA, Curityba, Paraná, n. 7-17, 1889.

A OPINIÃO, Curityba, Paraná, n. 1-8, 1887.

ARNAUT DE TOLEDO, Cézar de Alencar; SKALINSKI JUNIOR, Oriomar. A imprensa periódica como fonte para a história da educação: teoria e método. Revista HISDTEDBR - Online. Campinas, v. 12, n. 48, 2012. Disponível em: https://www.fe.unicamp.br/ revistas/ged/histedbr/article/view/4662/364. Acesso em: 15 abr. 2014.

ARNT, Héris. Jornalismo literário. Logos: Comunicação \& Universidade, Rio de Janeiro, v. 1, set. 1990 .

ARROYO, Leonardo. Literatura Infantil brasileira. São Paulo: Editora Unesp, 2011.

BASTOS, Maria Helena Camara. Impressos e cultura escolar: percursos da pesquisa sobre a imprensa estudantil no Brasil. La prensa pedagógica de los escolares y estudiantes. Su contribución al patrimonio histórico educativo. Salamanca: Ediciones Universidad de Salamanca., 2015. ( v. 1).

HAIDAR, Maria de Lourdes Mariotto. $\mathbf{O}$ ensino secundário no Império brasileiro. São Paulo: Gribaldo, USP, 1972.

JINZENII, Mônica Yumi. Imprensa periódica e juventude no século XIX. In: DAROS, Maria. das Dores; PEREIRA, Elaine. A. Teixeira. Sentidos da educação e projetos de Brasil: século XIX e XX. Belo Horizonte: Mazza Edições, 2017.

MACHADO, Maria Cristina Gomes. Estado e políticas da educação no Império brasileiro. In. SAVIANI, Dermeval. (org.). Estado e políticas educacionais na história da educação brasileira. Vitória: EDUFES, 2010.

MACHADO, Maria Cristina Gomes; RODRIGUES, Elaine. Conversas sobre fontes. In: GONDRA, José; MACHADO, Maria Cristina Gomes; SIMÕES, Regina Helena Silva (org.). História da educação, matrizes interpretativas e internacionalização. Vitória: EDUFES, 2017.

MACHADO, Maria Cristina Gomes. O Decreto de Leôncio de Carvalho e os Pareceres de Rui Barbosa em Debate: A criação da escola para o povo no Brasil no século XIX. In: STEPHANOU, Maria; BASTOS; Maria Helena Camara (org.). Histórias e memórias da educação no Brasil: século XIX. Petrópolis: Vozes, 2005.

MACHADO, Maria Cristina Gomes; MÉLO, Cristiane Silva. Rui Barbosa e a questão do ensino secundário no Diário de Notícias (1889). Revista Acta Scientiarum: Human and 
Social Sciences, v. 29, n. 2, p.183-193, 2007. Disponível em: \#ps://periodicos.uem. br/ojs/index.php/ActaSciHumanSocSci/article/view/918/445. Acesso em: 24 maio 2021.

MARTINELI, Laís Pacifico. Pelos estudantes e para os estudantes: a instrução e a literatura nos periódicos estudantis brasileiros (1870-1880). 2020, 406f. Tese (Doutorado em Educação) - Programa de Pós-Graduação em Educação, Universidade Estadual de Maringá, 2020.

NÓVOA, Antônio. A imprensa de educação e ensino: concepção e organização do repertório português. In: CATANI, Denice Barbara; BASTOS; Maria Helena Camara. (org.). Educação em revista: a imprensa periódica e a história da educação. São Paulo: Escrituras, 2002.

O ASPIRANTE. Rio de Janeiro, n. 1-12, 1881.

O ASPIRANTE. Rio de Janeiro, n. 13 e 14, 1882.

PALLARES-BURKE, Maria Lúcia Garcia. A imprensa periódica como uma empresa educativa no século XIX. Cadernos de Pesquisa, São Paulo, n. 104, p. 144-161, jul. 1998. Disponível em: http://publicacoes.fcc.org.br/index.php/cp/article/view/723/737. Acesso em: 16 jun. 2021.

28 PEREIRA, Milena da Silveira. A crítica que fez história: as associações literárias no Oitocentos. São Paulo: Editora Unesp Digital, 2015.

TOLEDO, Cézar de Alencar Arnaut de; SKALINSKI JUNIOR, Oriomar. A imprensa periódica como fonte para a história da educação: teoria e método. Revista HISDTEDBR - Online, Campinas, v. 12, n. 48, 2012. Disponível em: https://www.fe.unicamp.br/revistas/ $\mathrm{ged} / \mathrm{histedbr/article/view/4662/364.} \mathrm{Acesso} \mathrm{em:} 15$ abr. 2014.

VERÍSSIMO, José. A educação nacional. Fundação Biblioteca Nacional/ Departamento Nacional do Livro, 1915. (livro digital). 
Dra. Laís Pacifico Martineli

Universidade Estadual de Maringá (Brasil)

Programa de Pós-Graduação em Educação

Grupo de Estudos e Pesquisa em História da Educação, Intelectuais e Instituições Escolares (GEPHEIINSE)

Orcid id: https:/ / orcid.org/0000-0002-0977-644 1

E-mail: Ipmartineli@gmail.com

Dra. Maria Cristina Gomes Machado Universidade Estadual de Maringá (Brasil) Programa de Pós-Graduação em Educação Grupo de Estudos e Pesquisa em História da Educação, Intelectuais e Instituições Escolares (GEPHEIINSE) Orcid id: https:/ / orcid.org/0000-0002-7359-4562 E-mail: mcgmachado@uem.br

Recebido 21 jun. 2021 Aceito 26 jul. 2021 